Discussion Paper No. 06-011

Deregulating Job Placement in Europe:

A Microeconometric Evaluation of an Innovative Voucher Scheme in Germany

Henrik Winterhager, Anja Heinze and

Alexander Spermann

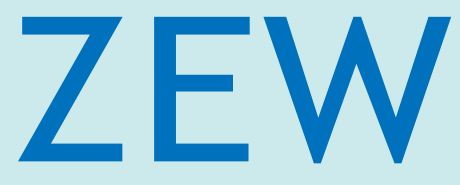

Zentrum für Europäische Wirtschaftsforschung $\mathrm{GmbH}$

Centre for European

Economic Research 
Discussion Paper No. 06-011

\section{Deregulating Job Placement in Europe: A Microeconometric Evaluation of an Innovative Voucher Scheme in Germany}

Henrik Winterhager, Anja Heinze and

Alexander Spermann

Download this ZEW Discussion Paper from our ftp server:

ftp://ftp.zew.de/pub/zew-docs/dp/dp06011.pdf

Die Discussion Papers dienen einer möglichst schnellen Verbreitung von neueren Forschungsarbeiten des ZEW. Die Beiträge liegen in alleiniger Verantwortung

der Autoren und stellen nicht notwendigerweise die Meinung des ZEW dar.

Discussion Papers are intended to make results of ZEW research promptly available to other economists in order to encourage discussion and suggestions for revisions. The authors are solely responsible for the contents which do not necessarily represent the opinion of the ZEW. 


\section{Non technical summary}

Job placement vouchers can be regarded as a tool to spur competition between public and private job placement activities. The German government launched this instrument in order to end the public placement monopoly and to subsidize its private competitors by means of job placement vouchers. Individuals unemployed for at least three months and eligible for unemployment benefits are entitled to a voucher. The Federal Employment Agency pays between 1,500 and 2,500 € per successful placement, depending on the duration of previous unemployment. This paper evaluates the causal effect of a voucher issue on the probability of regular employment.

The empirical analysis is based on very rich administrative data provided for the first time by the Federal Employment Agency. We apply propensity score matching as a method to solve the fundamental evaluation problem and to estimate the effect of an innovative job placement voucher scheme in Germany. We discuss in detail the plausibility of the identifying matching assumptions and argue that they should hold, i.e. the matched control group is a reliable proxy for the unobserved counterfactual. We define treatment in our evaluation design as "receipt of a first voucher during the unemployment spell” in May and June 2003, and outcome as employment within 12 months after voucher issue. Therefore, we compare voucher recipients to a matched control group of non-recipients.

Our results indicate that 12 months after the receipt of a voucher, 27.09 percent of the recipients are in regular employment, whereas only 20.60 percent of the matched control group are employed. This difference of 6.49 percentage points can be interpreted as the average treatment effect on the treated (ATT). Furthermore, the ATT is largest for vouchers with the lowest bonus and vice versa. Apparently, the higher cost for placing "bad risks" cannot be offset by the higher bonus.

Interestingly, deadweight plays a minor role with job placement vouchers. We highlight an efficiency measure based on a comparison of treatment effects and redeemed vouchers. According to this measure, the deadweight is negligible. 


\title{
Deregulating Job Placement in Europe: A Microeconometric Evaluation of an Innovative Voucher Scheme in Germany
}

\author{
Henrik Winterhager ${ }^{\# \star}$, Anja Heinze* and Alexander Spermann ${ }^{\star \circ}$ \\ * Centre for European Economic Research (ZEW Mannheim) \\ - University of Freiburg
}

This version: February 8, 2006

\begin{abstract}
Job placement vouchers can be regarded as a tool to spur competition between public and private job placement activities. The German government launched this instrument in order to end the public placement monopoly and to subsidize its private competitors. We exploit very rich administrative data provided for the first time by the Federal Employment Agency and apply propensity score matching as a method to solve the fundamental evaluation problem and to estimate the effect of the vouchers. We find positive treatment effects on the employment probability after one year of 6.5 percentage points in Western Germany and give a measure for deadweight loss.
\end{abstract}

JEL Classification: J 68, H 25

Keywords: Job Placement, Active Labor Market Policy, Matching

Acknowledgements: We would like to thank Friedhelm Pfeiffer for his precious advice and many hours of constructive discussion to clarify the evaluation design. We are grateful to Bernd Fitzenberger, Wolfgang Franz, Christian Göbel, Thomas Kruppe, Michael Lechner, Jeffrey A. Smith, Lars Vilhuber, and three anonymous referees for very helpful comments. A previous version of this paper was presented at the following conferences: EALE/SOLE San Francisco 2005, CEA Toronto 2005, Annual Congress of the Verein für Socialpolitik 2005, IAB Evaluation Conference Nuremberg 2005, ZEW Evaluation Conference Mannheim 2004. We thank all the participants for their comments. This project has been financed by the Institute for Employment Research of the Federal Employment Services (IAB). We thank the IAB for access to the data. The usual disclaimer applies.

\footnotetext{
\# Corresponding author: Henrik Winterhager, Centre for European Economic Research (ZEW), PO Box 103443, D-68034 Mannheim, Tel.: +49-621-1235-280; fax: +49-621-1235-225. E-Mail: winterhager@zew.de
} 


\section{Introduction}

In the nineties, an increasing number of European public employment services lost their placement monopoly. Since then, public and private services have coexisted in most OECD countries. Germany was one of the last European countries to deregulate its job placement market. The public monopoly was abolished as late as in 1994, but regulation remained strict in comparison with much more deregulated markets like Great Britain and the Netherlands (Walwei 1991, Buttler/Walwei 1995, OECD 2001 and Konle-Seidl 2002). In 2002, job placement was further deregulated giving most of the unemployed (length of unemployment more than 3 months) access to the private job placement market. Furthermore, the government introduced a voucher scheme in April 2002.

Whereas Australia and the Netherlands use auctions to contract out employment services to private agencies (Dockery/Stromback 2001, OECD 2003), job placement vouchers are a more liberal approach where voucher recipients have much consumer sovereignty: they are free to choose the private agency they want to approach. The government launched this new instrument in order to end the public placement monopoly and to subsidize private competitors by means of job placement vouchers. Individuals unemployed for at least three months and eligible for unemployment benefits are entitled to a voucher. The Federal Employment Agency pays between 1,500 and 2,500 € per successful placement, depending on the duration of previous unemployment. Therefore, job placement in Germany now takes place via three main channels. First, and most importantly, unemployed individuals seek jobs on their own initiative. From a survey among employers in 2004 (Kettner/Spitznagel 2005) we know that 84 percent of job matches are based on this channel. Second, job seekers turn to job centers for assistance (14 percent of matches). Third, they use private job placement agencies (2 percent). This third channel is to be strengthened by job placement vouchers making recipients more attractive customers for private agencies. This paper evaluates the causal effect of a voucher issue on the probability of regular employment. Public-sector caseworkers receive a salary whether they are successful in placing job seekers or not. As opposed to that, private agencies and their staff are profit-oriented and exposed to competition. Therefore we assume that private agencies work more effectively. A positive treatment effect may be expected, but we have to be cautious with respect to selection bias.

The paper is structured as follows: Section 2 is devoted to a detailed description of the job placement voucher scheme. Section 3 describes the administrative data set as well as the 
sample selection. Section 4 presents the fundamental evaluation problem and discusses the identifying assumptions of the matching approach. Section 5 reports the empirical results on average treatment effects on the treated estimated by propensity score matching. Section 6 concludes.

\section{Institutional features of job placement vouchers}

How do job placement vouchers work? Basically, it is a four-step procedure. (1) All individuals having been registered as unemployed for more than three months are eligible for vouchers. (2) There are two ways of obtaining vouchers. (2a) Individuals knowing about the vouchers ask for them and receive them. (2b) Caseworkers offer the voucher to (selected) individuals based on their subjective judgment. (3) The recipient may now sign a placement contract with a private placement agency. (4) If the agency finds a private sector job for the unemployed person and an employment contract is signed, the Federal Employment Agency will redeem the voucher to the private agency (like in a "bounty system”). ${ }^{1}$

The redemption amount is graduated. A first payment of $1,000 €$ is due immediately after the individual has taken up the job. (If employment terminates after less than three months, the agency has to pay back the money.) For an employment that lasts for more than six months, a bonus will be paid after these six months that depends on the duration of previous unemployment:

- $500 €$ after an unemployment duration of up to 6 months,

- $\quad 1,000 €$ after an unemployment duration of 6 to 9 months,

- $\quad 1,500 €$ after an unemployment duration of more than 9 months.

Vouchers are only valid for a period of three months, which means that the employment contract initiated by the private placement agency has to be signed within three months after the issue of the voucher. The employment itself may start later. In order to avoid misuse, only placements with employers for whom the recipient has never worked before are rewarded.

Caseworkers are not allowed to suggest specific agencies, but the agencies are allowed to advertise their services in the job center. Vouchers are an additional option for unemployed people, they cannot be forced to use them to find a private placement agency. Also, private 
agencies may refuse to accept vouchers if they think that they do not cover costs. However, Hagemann/Sörgel (2005a) find that by June 2004 more than 6,000 private agencies (or agents) had cashed in at least one voucher. Only 11 percent of the agencies achieved more than 12 successful placements. But together these larger agencies achieved 59 percent of the successful placements. Private agencies are present in all of the labor market districts.

\section{Data and sample selection}

The empirical analysis is based on data sets created by the Federal Employment Agency. They contain information on dates of voucher receipt and redemption. Furthermore, the job seekers' data base (Bewerberangebotsdatei) provides information on socio-economic characteristics, qualification, and recent labor market history. ${ }^{2}$ Additional information on the long term labor market history of each individual comes from the recently created integrated employment biographies data base (Integrierte Erwerbsbiografie, IEB). IEB is a composite data set created by the research institute of the Federal Employment Agency (IAB) for the purpose of evaluating Germany's latest labor market policy reforms and has not been used for evaluation studies before. IEB contains information on regular employment, unemployment benefits paid and participation in labor market programs thereby reducing unobserved heterogeneity.

We define the treatment as "receipt of a first voucher during the unemployment spell" in May and June 2003. From a survey among voucher recipients we know that about 79 percent of them did approach a private placement agency (Hagemann/Sörgel 2005b). We do not have this information in our micro data and we do not know which of the recipients actually signed a placement contract with a private agency. So we cannot evaluate the treatment "signing of a placement contract" which might seem more interesting to the reader. Instead, we can only use receipt as treatment. ${ }^{3}$ This parameter seems also relevant to us because it can be influenced more directly by the Federal Employment Agency than the signing of a

1 It must be a job with at least 15 weekly working hours lasting for a minimum of three months.

2 See Lechner et al. (2001) for a description of these data.

3 This means that "activation" effects of voucher receipt which might occur in addition to the intended functioning of the voucher are included in the estimated effects. 
contract. ${ }^{4}$ We concentrate on the first voucher in the unemployment period. The time frame of voucher provision had to be restricted to May and June of 2003 because data from the job seekers' data base dating back further than May 2003 was not available, and we aim to observe a time interval after the treatment that is sufficiently long.

We conducted separate analyses for Eastern and Western Germany, as the two regions still feature very different labor markets and handling of labor market programs. We focus on the results for Western Germany, those for Eastern Germany are available upon request.

We only included eligible individuals in the control group who were unemployed for at least one day in May and June 2003 and who have never received vouchers. The fact that part of the recipients (about 18\%) obtained a second voucher (or more) in their unemployment spell implies that we actually estimate the effect of being in the voucher scheme versus not being in the voucher scheme. As a sensitivity analysis, we allow non-recipients to receive a voucher two months later at the earliest. This implies estimating the effect of receiving a voucher now versus waiting for two months and possibly receiving a voucher then, as proposed by Sianesi (2004). We do not report the results of this later analysis: they are very similar because voucher take-up is low.

Participants in other active labor market programs at the reference date (like retraining or job creation schemes) are excluded from the control group. ${ }^{5}$ But we do not exclude recipients or non-recipients of vouchers who participated in such programs later on. So we implicitly view these policies as one possible consequence of receiving or not receiving a voucher. ${ }^{6}$

Descriptive statistics are presented in Table 1. More than 1.4 million individuals in Western Germany are eligible for job placement vouchers. 30,402 received a voucher in May and June 2003. ${ }^{7}$ Low participation may be due to the complicated design of vouchers. The selection process will be discussed in detail in Section 4.

4 There might be cases where a caseworker offers a voucher but the unemployed person does not take it. We do not observe those cases, therefore the Federal Employment Agency can still not control our parameter perfectly.

5 This means that we measure the effect of receiving the voucher versus using the placement services of the Federal Employment Agency without participating in any labor market program. Otherwise our estimated effect would be influenced by the effect of other programs.

6 This approach is also followed in Gerfin/Lechner (2002) and Sianesi (2004).

7 However, the percentage (2.11) in the table cannot be interpreted as the take-up rate. This has to be calculated by relating the 30,402 to a 2-months-inflow into eligibility, which produces about 5\%. For our 
Table 1

The characteristics of recipients and non-recipients are compared in table 2. Recipients are younger, better educated, and there are fewer females and foreigners among them.

Table 2

Although there is no fixed budget for job placement vouchers on the federal level inviting regional offices to compete for the largest share of an endogenous budget, the data reveal huge variations between the labor market districts in the take-up rate. We could not find a systematical relationship of this variation to regional labor market conditions (unemployment rate, vacancy rate, rate of short time work, and other labor market policies).

\section{Identification and estimation methods}

\subsection{The evaluation problem and identifying assumptions}

We formalize our evaluation issue in the potential outcome framework. ${ }^{8}$ Let $D_{i}$ be a dummy variable that takes the value 1 if the unemployed person receives a voucher and 0 otherwise. Let $\mathrm{Y}_{\mathrm{i}}$ be the observed outcome variable which is 1 if the individual is in regular employment at a given date. More precisely, $\mathrm{Y}_{1 \mathrm{i}}$ is the outcome in case of treatment and $\mathrm{Y}_{0 \mathrm{i}}$ is the outcome in case of non-treatment, so $\mathrm{Y}_{\mathrm{i}}=\mathrm{D}_{\mathrm{i}} \mathrm{Y}_{1 \mathrm{i}}+\left(1-\mathrm{D}_{\mathrm{i}}\right) \mathrm{Y}_{0 \mathrm{i}} \cdot{ }^{9}$. We are actually interested in the treatment effect

study we use the stock sample, because using a flow sample would only allow us to estimate the effect for the very short term unemployed given the time frame of our data. This approach is also used in Gerfin/Lechner (2002), for example. 2.11 is the percentage of recipients in this stock sample. Using a stock sample means that individuals in long term unemployment are overrepresented in comparison to a flow sample. So it seems useful to look at the effects for different unemployment durations distinctly, as we will do later on.

8 For a survey on evaluation methods and literature see Heckman, LaLonde and Smith (1999), Blundell and Dias (2002), Angrist and Krueger (1999).

9 This representation requires the stable unit-treatment value assumption (SUTVA, see Rubin, 1980). For this assumption to hold there must not be any indirect effects of the job placement vouchers. We would expect 
$\Delta_{i}=Y_{1 i}-Y_{0 i}$.

However, it is never possible to observe $Y_{1 \mathrm{i}}$ and $\mathrm{Y}_{0 \mathrm{i}}$ for the same individual at the same time, so that $\Delta_{i}$ cannot be measured directly. This so-called fundamental evaluation problem can be solved if non-testable identifying assumptions hold. The parameter of interest in most evaluation studies is the average effect of treatment on the treated (ATT):

$A T T=E\left(Y_{1}-Y_{0} \mid D=1\right)=E\left(Y_{1} \mid D=1\right)-E\left(Y_{0} \mid D=1\right)$.

In our setting, this parameter would measure the average change in employment probability of voucher recipients that was actually caused by that voucher. A set of assumptions under which the ATT can be identified is the following:

$Y_{0} \perp D \mid X$

$\operatorname{Pr}(D=1 \mid X)<1$

Assumption (3) is the Conditional Independence Assumption (CIA). It is a critical assumption, because all characteristics that influence both treatment and outcome at the same time have to be observed. We will discuss this assumption in section 4.2. Assumption (4) implies that there is common support.

\subsection{Plausibility of the Matching Assumptions}

For the non-testable CIA to be likely to hold, we would have to be able to observe all the criteria which influence both treatment probability and outcome in the case of non-treatment. This assumption has to be discussed in relation to the available data set and the selection process. There are usually two agents involved in the selection process: the caseworker and the unemployed person. The issue of the voucher can be initiated by both.

A survey among caseworkers and voucher recipients (Hagemann/Sörgel 2005b) ${ }^{10}$ allows us to analyze the stages of the selection process (self selection and administrative selection). 30 percent of the voucher recipients said they obtained information about the voucher from the

the job placement vouchers to have substitution effects on non-recipients. However, voucher take-up rates are low and the majority of job matches occurs as a result of the individual's own search or through public placement agencies. Thus indirect effects are negligible (see Hujer/Zeiss, 2004, for a macroeconometric approach). 
notice-board in the job center or from leaflets, 28 percent mentioned the media, and another 28 percent relatives or friends (more than one answer was possible). This shows that betterinformed individuals select themselves into the program. Administrative selection is more complicated. The caseworkers' motivation may be twofold. On the one hand, caseworkers compete with private placement agencies if they think their reputation depends on their relative performance. Consequently, caseworkers would tend to assign those individuals to their competitors who are most unlikely to be placed successfully. On the other hand, caseworkers' caseload tends to be very high so that the private agencies may help them reduce their work load. This would create the incentive to assign those individuals to the competitors who benefit most from private placement services, because otherwise they might be back very soon. The same would occur if we assumed altruistic behavior of caseworkers trying to improve their clients' chances for employment. A survey among managers responsible for job placement vouchers in the job centers in Hagemann/Sörgel 2005b shows that vouchers tend to be offered to younger persons with higher qualifications and better placement chances. We can also see from the data that it is much more unlikely for the long-term unemployed to receive vouchers. We conclude that the administrative selection process appears to yield a positive selection of individuals.

We would conclude that the probability of receiving a voucher is higher where caseworkers see good employment chances and where individuals are better informed about available job search channels, which should be true for the more active job seekers. In the following we will argue that there is sufficient information in the data to account for this selection.

Self selection of individuals and the caseworkers' assessment of their employment prospects will depend on the following characteristics of the individual, which can be also observed in the data:

- socio-demographic attributes such as gender, age, nationality, marital status, childcare responsibilities, and health status

- the qualification of the unemployed: secondary school qualifications, vocational training, and actual qualification level as judged by the caseworker; this last variable is an important indicator of the caseworker's assessment of the employment prospects

10 A random sample $(\mathrm{N}=6,000)$ was drawn for this survey. There were 1,290 respondents. Among these respondents, men and individuals under 35 years were underrepresented (14 respectively 8 percentage points). 
- information about the job the person is looking for: preferred working time, occupation, and experience in that occupation according to the assessment of the caseworker

- the individual's recent labor market history is important information for the caseworker, providing the duration of unemployment, the level of unemployment benefits or assistance, the industry, wage, and length of employment in the last job, whether the individual was laid off by the employer, chose to quit or had a fixed-term contract.

However, the caseworkers' assessment will also depend on their perception of the social skills of their clients and their motivation. Motivation plays an important part in self selection, too: Individuals who are better motivated will be more likely to obtain information about the voucher and more willing to look for and approach a private placement agency. We cannot observe these important "soft factors" directly. But on the one hand, they will be correlated with the observed variables listed above.

On the other hand, we think that most of what is left will largely be reflected in the employment history of the individual. The employment history was shown to be very important for the identification of the causal effect by matching (e.g. Heckman et al. 1998). In our data set, we have daily information on the status of the individual during the last five years. Possible states are employment, unemployment, participation in two labor market programs, and out of the labor force. Having a large sample, we were able to use this information in a very detailed way. We constructed 96 dummy variables representing employment history (six time intervals before voucher receipt times four labor market states times four categories for certain shares of time spend in each state per time interval).

To summarize, we believe there is sufficient information on the unemployed individuals to be able to sufficiently approximate the criteria which influence treatment and outcome in case of not using a voucher. Note that we have more detailed information in our data than other evaluation studies using matching, e.g. Dorsett (2005) and Heckman/Smith (2004). If the reader agrees that the CIA is plausible, we can estimate the average effect of treatment on the treated by matching.

Random variation in the treatment conditional on $\mathrm{X}$, which is needed to achieve common support, could result from varying opinions on the general usefulness of private placement agencies, both on the side of the caseworkers and of the unemployed. These opinions should not influence the outcome in case of non-receipt, having controlled for the above covariates. 


\subsection{Econometric strategy}

Under assumptions (3) and (4) the counterfactual outcome for the recipients (and thus the ATT) can be estimated: for a recipient with characteristics $X$ the average outcome of all the non-recipients with $X$ is a consistent estimate of the counterfactual. But in practice, if $X$ is large and contains many continuous variables, there will be lots of recipients for whom no exact match exists (the "curse of dimensionality”, Heckman et al., 1997). We overcome this obstacle by applying propensity score matching: Recipients and non-recipients are matched based on their estimated probability to belong to the treatment group $(P(X))$. Rosenbaum and Rubin (1983) show that matching on $P(X)$ produces consistent estimates of the treatment effect. However, Dehejia and Wahba (2002) point out that it is important to choose the specification of the propensity estimation carefully in order to balance the covariates. We apply nearest neighbour matching with replacement which matches each recipient to the non-recipient with the closest $P(X)$.

For the calculation of standard errors of the ATT, we assume independent observations, fixed weights, and homoskedasticity of the outcome variable within the treatment group and the control group (see Lechner, 2001). We use the following formula proposed by Lechner (2002) to calculate the standard errors:

$\operatorname{Var}(A T T)=\frac{1}{N_{1}} \operatorname{Var}\left(Y_{1} \mid D=1\right)+\frac{\sum_{j=1}^{N_{0}} \omega_{j}^{2}}{\left(N_{1}\right)^{2}} \operatorname{Var}\left(Y_{1} \mid D=0\right)$,

where $N_{1}$ is the number of treated individuals and $\omega_{j}$ is the weight of observation $\mathrm{j}$ in the matching. We will use this equation, which assumes that the variance is not influenced by the fact that the propensity score is an estimated variable, to calculate the approximate standard errors of the ATT.

A practical problem associated with matching follows from the fact that some of the covariates as well as the outcome variable are measured with respect to the voucher issue date. However, such a starting date does not exist for non-recipients. We use a method proposed by Lechner (1999) to account for this issue. ${ }^{11}$ The starting dates for non-recipients are drawn at random from the distribution of recipients' starting dates. This generates a distribution of starting dates for the non-recipients which converges to the distribution for 
the recipients (all in May and June 2003). If such a hypothetical starting date does not coincide with the institutional frame, i.e. if non-recipients are not eligible at the respective starting date, the observation is deleted. This should not seem too controversial because the control group is made up of eligible individuals who were unemployed for at least one day in May and June 2003.

\section{Empirical results}

\subsection{Propensity Score Estimation}

The propensity score is estimated by maximising a likelihood function based on a standard probit equation, where - according to the CIA - the variables are included which should influence both the probability of treatment as well as the outcome in the non-treated state. Economic theory and an implementation study provide some guidance in choosing the relevant variables. We distinguish between six sets of variables: socio-demographic attributes, qualification, information about the last contact with the labor market, information about the favoured new job, recent labor market history, and regional indicators.

Estimation results are available upon request or can be found in Heinze et al. (2004). We will comment on selected variables only. As in most labor market programmes the results show that the participation probability decreases with age. Foreigners have a significantly lower probability of receiving vouchers. Women have a lower probability of receiving a voucher than men. Regarding marital status, the results show that individuals who are married have a higher participation probability than singles. A selectivity of treatment with respect to vocational training is not found because the effect is absorbed by interaction terms with occupational field. We find that individuals with higher qualification from caseworkers' perspective have a higher probability of receiving a voucher than those without qualification.

\subsection{Quality of the matching}

Figure 1 shows that common support for all treated individuals is achieved. ${ }^{12}$ Furthermore, the matching estimator is successful in balancing out observable pre-treatment differences

11 A similar procedure is used by Larsson (2003).

12 We have cut off the figure above 600 observations in order to make this discernible for higher values of the propensity score. 
between voucher recipients and the matched control group. ${ }^{13}$ Before matching, several of the covariates have standardized differences bigger than 20. After matching, all the variables have standardized differences of less than 2 , which is a very good value. ${ }^{14}$ We also used a Hotelling $\mathrm{T}^{2}$ test of the joint null hypothesis of equal means for all of the variables included in the matching between the treatment group and the matched control group. ${ }^{15}$ This null hypothesis cannot be rejected.

Figure 1

\subsection{Treatment effects and efficiency considerations}

The estimated ATT of the voucher's receipt on being in regular employment in the months afterwards is presented in table 3. One month after the receipt of a voucher, 8.6 percent of the recipients are in regular employment, whereas only 5.7 percent of the matched control group are employed. The difference of 2.9 percentage points can be interpreted as the ATT. It rises to 6.1 percentage points after 3 months and 6.5 percentage points after 12 months. This pattern can be explained by the fact that the voucher is valid for three months.

Table 3

Column 6 shows the share of issued vouchers which was redeemed by the Federal Employment Agency up to that time, regardless of whether the corresponding job still existed. Comparing this with the share of recipients in regular employment (column 2) and the ATT (column 4) yields interesting insights in efficiency issues. First, the percentage of redeemed vouchers is smaller than the percentage of recipients in employment. Therefore, some of the recipients successfully find jobs via other channels than vouchers. Second, a conventional measure of deadweight loss is the share of the control group who found a job.

\footnotetext{
13 The results of the balancing tests are available upon request.

14 There is no critical value for the standardized difference given in the literature, but Rosenbaum and Rubin (1985) suggest that a value of 20 is "large".

15 This test is used by Smith and Todd (2004).
} 
This is about 21 percent after 12 months in our case. However, for this instrument we propose a more appropriate efficiency measure similar to Michalopoulos et al. (2005): the estimated ATT relative to the redeemed vouchers. We observe that the share of redeemed vouchers after one year is larger than the estimated ATT, because some of the successful recipients would have found a job anyway. Note that only redeemed vouchers are associated with fiscal cost. Because the difference between the two numbers is very small (only 0.9 percent after 12 months), the use of the instrument seems to be quite efficient from the Federal Employment Agency's perspective. A detailed complementary cost-benefit analysis is beyond the scope of this paper (see Pfeiffer and Winterhager, 2004 for such an analysis).

Recall that bonuses paid to private placement agencies after six months of employment depend on durations of unemployment. The bonus varies between $500 €$ (unemployed for less than six months) and 1,500 $€$ (unemployed for more than nine months). Interestingly, the ATT is largest for vouchers with the lowest bonus and vice versa. ${ }^{16}$ Apparently, the higher cost for placing "bad risks" cannot be offset by the higher bonus. There are no differences between the treatment effects for males and females, whereas younger individuals (under 25) have much higher effects than those between 25 and 50 and above 50: 10.6 percentage points versus 6.3 and 4.5 percentage points after one year.

The results for East Germany cannot be presented in detail here, but they confirm the West German results. The estimated ATT after 12 months is 5.8 percentage points.

\section{Conclusions}

For a microeconometric analysis of an innovative job placement voucher scheme in Germany, we apply matching as a method to solve the fundamental evaluation problem. We discuss the plausibility of the identifying matching assumptions and argue that they should hold, i.e. the matched control group is a reliable proxy for the unobserved counterfactual. First, we think that the CIA should hold, because the available highly informative administrative data provided for the first time by the Federal Employment Agency minimizes selection on unobservables. Unobserved heterogeneity should be small enough to get a negligible bias. Second, the common support is given because selection into the program is not deterministic due to job seekers' and caseworkers' idiosyncratic preferences. Third, the stable unit-treatment value assumption holds due to the very low take-up rate of 
about 5 percent of those eligible. We therefore think that we can separate selection and causal effects.

We define treatment in our evaluation design as issuing vouchers, and outcome as employment within 12 months after voucher issue. Therefore, we compare voucher recipients to a matched control group of non-recipients. Individuals received treatment in May and June 2003. Outcome is observable within twelve months (up to June 2004) after the program group has started job search with vouchers.

We find positive average treatment effects on the treated of 6.5 percentage points for West Germany one year after voucher receipt. The main message to German policy makers based on our microeconometric analyses is that the voucher scheme should be continued. However, this assessment might change once macroeconometric and cost-benefit analyses are taken into account. As the effects are smaller for the long term unemployed and older individuals, functional alternatives should be considered for these groups.

Interestingly, deadweight plays a minor role with job placement vouchers. We highlight an efficiency measure based on a comparison of treatment effects and redeemed vouchers. According to this measure, the deadweight is negligible. Traditional measures like the share of controls in regular employment indicating a much higher deadweight loss, are not an appropriate efficiency measure in this case.

Future research should compare the effectiveness of the voucher scheme to that of the new system of contracting out placement services to private agencies which was installed in Germany in 2004. This system is more similar to the systems in Australia and the Netherlands. It would be useful to know which of these systems is more effective in moving certain groups of jobless people back into work.

16 The three ATTs after one year are 7.7, 6.4, and 3.3 percentage points respectively. 


\section{References}

Angrist, J. D. and A. Krueger (1999). "Empirical Strategies in Labor Economics." The Handbook of Labor Economics. O. Ashenfelter and D. Card. North-Holland. Vol. 3A: 1277-1366.

Blundell, R. und M. Costa Dias (2002). "Alternative approaches to evaluation in empirical microeconomics." Portuguese Economic Journal, Vol. 1 Issue 2, 91-116.

Buttler, F. and U. Walwei (1995). "Different Institutional Arrangements for Job Placement." Institutional Frameworks and Labor Market Performance. F. Buttler, W. Franz, R. Schettkat, D. Soskice. Routledge. London and New York: 248-269.

Dehejia, R. H. and S. Wahba (2002). "Propensity Score Matching Methods for Nonexperimental Causal Studies." Review of Economics and Statistics 84(1): 151161.

Dockery, A. M. and T. Stromback (2001). "Devolving public employment services: Preliminary assessment of the Australian experiment." International Labour Review. 140(4): 429-451.

Dorsett, R. (2005). "The new deal for young people: effect on the labour market status of young men." Labour Economics (forthcoming).

Gerfin, M. and M. Lechner (2002): "A Microeconometric Evaluation of the Active Labour Market Policies in Switzerland", Economic Journal 112, 854-893.

Hagemann, S. and W. Sörgel (2005a). "Vermittlungsgutscheine, Teil VII, Implementationsund Strukturanalysen - Private Arbeitsvermittler" IAB-Forschungsbericht 6/2005."

Hagemann, S. and W. Sörgel (2005b). "Vermittlungsgutscheine, Teil VII, Implementationsund Strukturanalysen, Tabellenanhang" IAB-Forschungsbericht 7/2005.

Heckman, J., H. Ichimura, J. Smith and P. Todd (1998). "Characterizing Selection Bias Using Experimental Data." Econometrica 66(5): 1017-1098.

Heckman, J., H. Ichimura and P. Todd (1997). "Matching as an Economic Evaluation Estimator: Evidence from Evaluating a Job Training Program." The Review of Economic Studies 64(4): 605-654.

Heckman, J., R. LaLonde and J. Smith (1999). The Economics and Econometrics of Active Labor Market Programs. Handbook of Labor Economics. O. Ashenfelter and D. Card. North-Holland. Vol. 3: 1865-2097.

Heckman, J., J. Smith (2004). “The Determinants of Participation in a Social Program: Evidence from a Prototypical Job Training Program.” Journal of Labor Economics. 22(4): 243-298.

Heinze, A., F. Pfeiffer, A. Spermann and H. Winterhager (2005). "Vermittlungsgutscheine, Teil III, Mikroökonomische Wirkungsanalyse." IAB-Forschungsbericht 3/2005.

Hujer, R. and C. Zeiss (2005). "Vermittlungsgutscheine, Teil IV, Makroökonomische Wirkungsanalyse." IAB-Forschungsbericht 4/2005.

Kettner, A. and E. Spitznagel (2005). "Gesamtwirtschaftliches Stellenangebot gering" IABKurzbericht 6/2005. 
Konle-Seidl, R. (2002). "Steigerung von Effizienz und Reputation in der Arbeitsvermittlung." IAB-Werkstattbericht 15/2002.

Larsson, L. (2003). "Evaluation of Swedish youth labour market programmes." Journal of Human Resources 2003, 38(4): 891-927.

Lechner, M. (1999). "Earnings and Employment Effects of Continuos Off-the-Job Training in East Germany After Unification." Journal of Business \& Economic Statistics 17(1): 74-90.

Lechner, M. (2001). "Identification and Estimation of Causal Effects of Multiple Treatments Under the Conditional Independence Assumption." Econometric Evaluation of Labour Market Policies. M. Lechner and F. Pfeiffer. Heidelberg, ZEW. Vol. 13: 4358.

Lechner, M. (2002). "Some practical issues in the evaluation of heterogeneous labour market programmes by matching methods." Journal of the Royal Statistical Society 165: 5982.

Lechner, M., F. Pfeiffer, H. Spengler and M. Almus (2001). "The Impact of Non-Profit Temping Agencies on Individual Labour Market Success." Econometric Evaluation of Labour Market Policies. M. Lechner and F. Pfeiffer. Heidelberg. Vol. 13: 211242.

Michalopoulos, C., P. Robins and D. Card (2005): "When financial work incentives pay for themselves: evidence from a randomized social experiment for welfare recipients." Journal of Public Economics 89, 5-29.

OECD (2001). "Labour Market Policies and the Public Employment Service." Paris.

OECD (2003). "The Competitive Market for Employment Services in the Netherlands." OECD Social, Employment and Migration Working Paper.

Pfeiffer, F. and H. Winterhager (2005). "Vermittlungsgutscheine, Teil V, Kosten-NutzenAnalyse." IAB-Forschungsbericht 5/2005.

Rosenbaum, P. and D. Rubin (1983). "The Central Role of the Propensity Score in Observational Studies for Casual Effects." Biometrika 70: 41-55.

Rosenbaum, P. and D. Rubin (1985). "Constructing a Control Group Using Multivariate Matched Sampling Methods That Incorporate the Propensity Score." American Statistician 39: 33-38.

Rubin, D. (1980). "Comment of Badu, D. - Randomization Analysis of Experimental Data: The Fisher-Randomization Test." Journal of the American Statistical Association 75: 591-593.

Sianesi, B. (2004). "An Evaluation of the Swedish System of Active Labor Market Programs in the 1990s." Review of Economics and Statistics 86(1): 133-155.

Smith, J. and P. Todd (2004). "Does Matching Overcome LaLondes Critique of Nonexperimental Estimators?" Journal of Econometrics: 125(1-2): 305-353.

Walwei, U. (1991): "Job Placement in Europe, An International Comparison." Intereconomics 26: 248-254. 


\section{Appendix}

Table 1: Eligibility and issue of vouchers in May and June 2003 as well as redemption of vouchers for Western Germany

\begin{tabular}{lrrrr}
\hline & number & percentage & & \\
unemployed & $2,420,882$ & 100 & & \\
eligible & $1,438,156$ & 59.41 & 100 & \\
voucher obtained & 30,402 & & 2.11 & 100 \\
voucher redeemed & 2,371 & & & 7.78 \\
\hline
\end{tabular}


Table 2: Descriptive statistics (mean and value of a unit respectively) for recipients and nonrecipients, selected attributes (Western Germany)

\begin{tabular}{|c|c|c|}
\hline observations & $\begin{array}{r}\text { recipients } \\
30,402 \\
\end{array}$ & $\begin{array}{c}\text { non - } \\
\text { recipients } \\
1,407,754\end{array}$ \\
\hline variable & \multicolumn{2}{|c|}{ mean/ share } \\
\hline \multicolumn{3}{|l|}{ general socio-demographic attributes } \\
\hline age (in years) & 37.43 & 41.14 \\
\hline foreign & $13.70 \%$ & $16.96 \%$ \\
\hline female & $34.20 \%$ & $38.03 \%$ \\
\hline children 0 - 3 years & $5.04 \%$ & $3.85 \%$ \\
\hline children 3 - 7 years & $8.85 \%$ & $8.66 \%$ \\
\hline children 7 - 14 years & $10.35 \%$ & $10.24 \%$ \\
\hline \multicolumn{3}{|l|}{ vocational training (reference: without complete training ) } \\
\hline on-the-job vocational training & $54.51 \%$ & $46.73 \%$ \\
\hline classroom vocational training & $3.63 \%$ & $2.14 \%$ \\
\hline technical college & $4.67 \%$ & $4.13 \%$ \\
\hline university & $3.41 \%$ & $3.18 \%$ \\
\hline polytechnic & $2.18 \%$ & $1.73 \%$ \\
\hline \multicolumn{3}{|c|}{ qualification as seen by the caseworker (reference: no specialized knowledge) } \\
\hline top executive & $0.05 \%$ & $0.06 \%$ \\
\hline university level & $2.91 \%$ & $2.68 \%$ \\
\hline polytechnic level & $2.29 \%$ & $1.88 \%$ \\
\hline technical school level & $2.91 \%$ & $2.30 \%$ \\
\hline skilled workers & $49.04 \%$ & $39.21 \%$ \\
\hline others & $1.79 \%$ & $2.19 \%$ \\
\hline \multicolumn{3}{|l|}{ information about working history (short time) } \\
\hline existing professional experience in desired occupation & $85.61 \%$ & $87.45 \%$ \\
\hline daily wage of last employment $(€)$ & 30.60 & 27.68 \\
\hline daily amount of unemployment benefits / assistance (€) & 22.75 & 21.62 \\
\hline duration of unemployment until issue (days) & 330.98 & 469.75 \\
\hline
\end{tabular}


Table 3: Estimated Average Treatment Effect on the treated in Western Germany (regular employment after treatment); for recipients: share of issued vouchers which is redeemed

Share in regular employment for recipients: share of issued

months after issue of voucher

\begin{tabular}{rrrrr}
\hline recipients & $\begin{array}{c}\text { matched } \\
\text { control group }\end{array}$ & difference & std. error $\begin{array}{l}\text { vouchers which } \\
\text { is redeemed } \\
\text { (cumulative) }\end{array}$ \\
\hline $8.61 \%$ & $5.71 \%$ & $2.90 \%$ & $0.22 \%$ & $3.37 \%$ \\
$14.64 \%$ & $9.75 \%$ & $4.89 \%$ & $0.28 \%$ & $4.77 \%$ \\
$19.01 \%$ & $12.96 \%$ & $6.05 \%$ & $0.31 \%$ & $5.69 \%$ \\
$21.52 \%$ & $15.03 \%$ & $6.49 \%$ & $0.33 \%$ & $6.07 \%$ \\
$23.67 \%$ & $16.98 \%$ & $6.69 \%$ & $0.35 \%$ & $6.62 \%$ \\
$22.70 \%$ & $16.96 \%$ & $5.74 \%$ & $0.35 \%$ & $6.90 \%$ \\
$24.25 \%$ & $18.42 \%$ & $5.83 \%$ & $0.36 \%$ & $7.15 \%$ \\
$27.09 \%$ & $20.60 \%$ & $6.49 \%$ & $0.37 \%$ & $7.40 \%$ \\
\hline
\end{tabular}

Figure 1: Common support for Western Germany

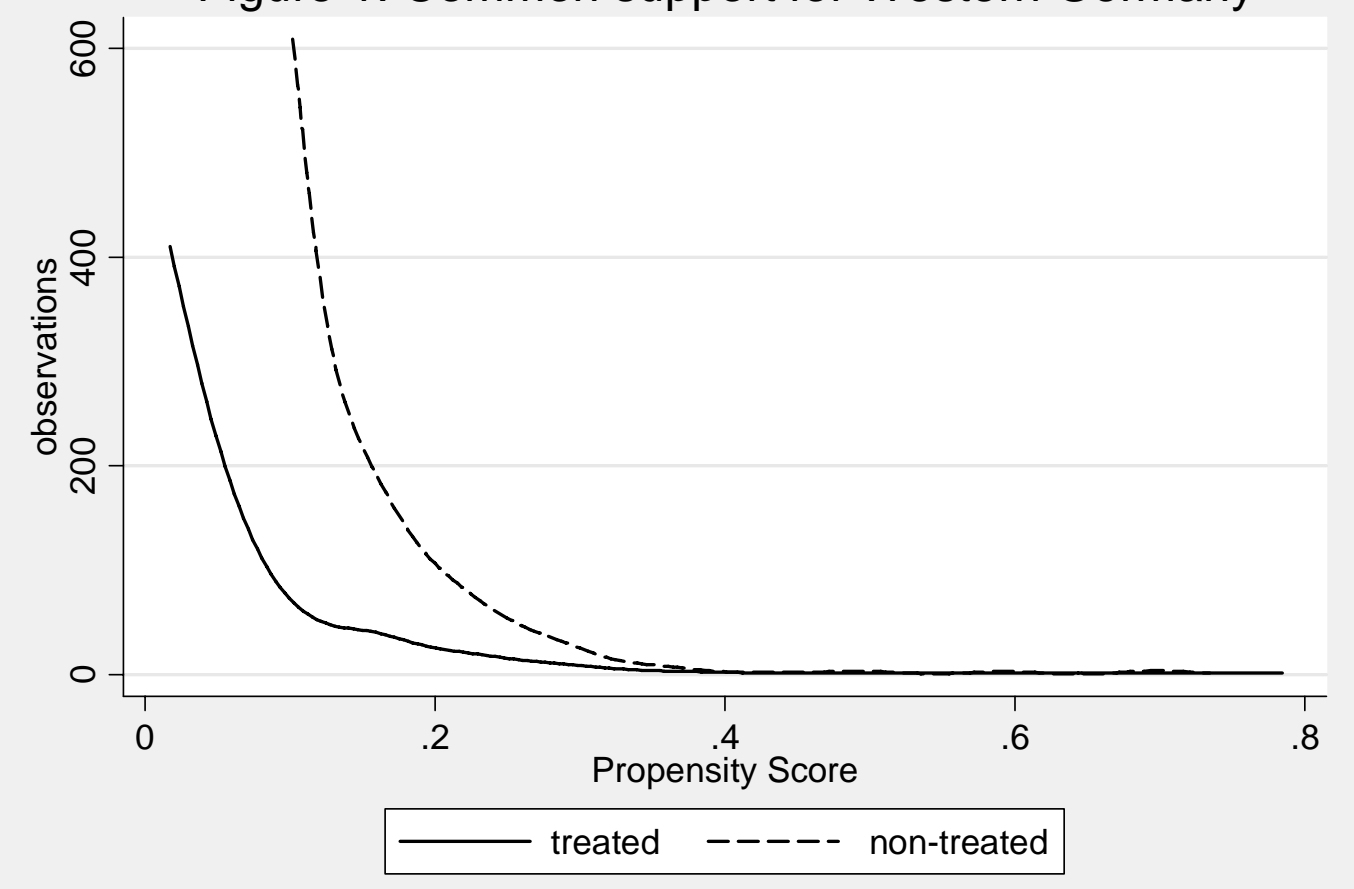

